\section{UJMM

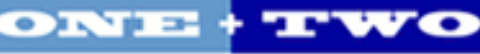

Volume 6 | 2016 Spring 2016

\section{Undergraduate Journal of Mathematical}

Modeling: One + Two

2016

\title{
Optimization of an Agitated Extractor
}

Evan Zapf

University of South Florida, zapf1@mail.usf.edu

Advisors:

Brian Curtin, Mathematics and Statistics

Scott Campbell, Chemical and Biomedical Engineering

Problem Suggested By: Scott Campbell

Follow this and additional works at: https://digitalcommons.usf.edu/ujmm

Part of the Chemical Engineering Commons, and the Mathematics Commons

UJMM is an open access journal, free to authors and readers, and relies on your support:

Donate Now

\section{Recommended Citation}

Zapf, Evan (2016) "Optimization of an Agitated Extractor," Undergraduate Journal of Mathematical Modeling: One + Two: Vol. 6: Iss. 2, Article 5.

Available at: https://digitalcommons.usf.edu/ujmm/vol6/iss2/5 


\title{
Optimization of an Agitated Extractor
}

\begin{abstract}
In this scenario, we use calculus to determine the optimal operating specifications of a chemical extraction process. The results are achieved by first developing an expression that yields the total annual cost of the process. Factoring in electricity, vessel, agitator, and solvent costs, an annual cost expression was fabricated. AGIEX company manufactures a certain amount of a product, A, which has an impurity that it wishes be reduced. By engineering an optimally sized vessel to perform the extraction of impurity, the company will save costs by ensuring no inefficient spending on power or excess solvent occurs. A specific amount of electricity is required to operate this vessel during extraction batches. These values of optimal vessel volume and power usage per batch ultimately form the boundaries of this streamlined system for the company.
\end{abstract}

\section{Keywords}

optimal, chemical extraction, vessel volume

\section{Creative Commons License}

(c) $($ ) $\ominus$

This work is licensed under a Creative Commons Attribution-Noncommercial-Share Alike 4.0 License. 


\section{PROBLEM STATEMENT}

The goal of this project is to optimize a chemical extraction process. AGIEX makes a $10,000 \mathrm{~kg} / \mathrm{yr}$ of a liquid product $A$ that contains an impurity at a concentration of $X_{0}=0.1 \mathrm{~kg}$

of impurity $/ \mathrm{kg}$ of $A$. AGIEX wishes to reduce the impurity level to $X=0.01$ before selling the product and decides to accomplish this with batch extraction. In this process, $N_{A} \mathrm{~kg}$ of the original product stream $A$ is mixed with $N_{B} \mathrm{~kg}$ of an immiscible solvent $B$ in an agitated extraction vessel for a period of $T$ hours that is sufficient to ensure that the two phases reach equilibrium. Most of the impurity in product $A$ transfers to solvent $B$ during this time. The two phases are separated into the final product $A$ with impurity concentration $X=0.01$ and the impurity rich solvent $B$ with impurity concentration of $Y(\mathrm{~kg}$ impurity $/ \mathrm{kg}$ of $B$ ). The batch process is operated $\mathrm{n}$ times per year until all $10,000 \mathrm{~kg}$ of product have been purified. The process is illustrated below:

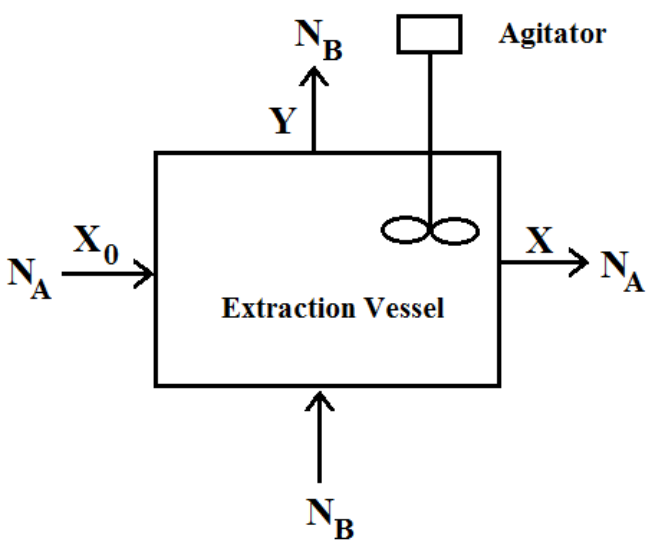

Figure 1: Extraction Vessel with Agitator

Using the optimal agitator power and vessel capacity, find the corresponding batch time, hours per year of operation, and number of batches per year of a chemical extraction process. Then, using these determined values, write an annual cost equation to find the annual cost of the process operation. 


\section{MOTIVATION}

The underlying importance of this exercise in mathematics is to limit unnecessary spending by AGIEX. The principles put forth by industrial engineers are to understand project decisions and to subsequently make these projects better. In this particular case, the company in discussion has made a corporate decision to reduce impurity levels in product $A$, by using solvent, $B$. Thus, after understanding this established scenario, we work to create procedures that ensure operation occurs at minimal cost and maximum efficiency. This includes developing an appropriately sized vessel in which extraction occurs - one that takes into consideration batch size, energy costs, and the capacity of the vessel itself.

Immiscibility properties in different liquid products permit instances of extraction of impurities within these and other products. Automated processes are being developed wherein organic solvents are being utilized to extract a wide range of drugs or pollutants. Using hollow fibers as micro-versions of vessels, researchers have been able to apply these findings in (Stewart) separation of these impurities from water, plasma, and other liquid substances (Esrafili). There exist real cost benefits to these methods as well. Fumaric acid has been applied to many major chemical processes, including food production and the light industry. To eliminate runoff and pollution of this substance while saving money in operations, "solvent extraction has been widely used to remove efficiently organic acids from industrial effluents to environmentally acceptable levels or to recycle the organic acids back to the original process" (Li).

Standardizing a system not only eliminates excess spending, but also warrants new sets of focalized conducting procedures of the system. It follows that in order for the operations sector of this business to take advantage of the cost reduction analysis, the operations must be 
performed in such a way that they adhere to the guidelines that support the cost reduction results. This communication between those who implement the new system and those who financially justify it cannot be dissonant. The importance of these methods and results cannot be overlooked, for the purpose is vital to the success of the project and corporate survival.

\section{MATHEMATICAL DESCRIPTION AND SOLUTION APPROACH}

\section{A. Governing equations, relationships and costs}

Given to us are many relationships between variables and the optimal values we are looking for. These include:

i. $\quad$ Mass balance on the impurity for one batch:

$$
N_{A} X_{0}=N_{A} X+N_{B} Y
$$

where $N_{A}$ and $N_{B}$ are the amounts of product $A$ and solvent $B$, respectively. $X$ and $Y$ are the impurity levels of product $A$ and $B$, respectively, with $X_{0}$ being the initial concentration before addition of any solvent $B$. The desired $X$ value after the addition of solvent $B$ is $0.01 . X_{0}$ is equal to 0.1 . The company makes $10,000 \mathrm{~kg} / \mathrm{yr}$ of product $A$.

\section{ii. Equilibrium relation:}

$$
Y=K X
$$

where $K$ is a partition coefficient with a value of 5 in this circumstance.

iii. Vessel volume:

$$
V=v_{A} N_{A}+v_{B} N_{B}
$$

where $v_{A}=1.2 \frac{\mathrm{L}}{\mathrm{kg}}$ and $v_{B}=1 \frac{\mathrm{L}}{\mathrm{kg}}$ are the specific volumes of product $A$ and solvent $B$, respectively. 
iv. Batch time:

$$
T=10 V^{0.5} P^{-1.2}
$$

where $P$ is the agitator power in $k W$.

v. $\quad$ Cost of the vessel (annually):

$$
C_{V}=20 V^{0.6}
$$

vi. $\quad$ Cost of the agitator (annually):

$$
C_{A}=90 P^{0.7}
$$

Other given values include electricity cost: $\frac{\$ 0.1}{k W \cdot h r}$ the cost of solvent $B: \frac{\$ 0.05}{k g}$

\section{B. Solution}

The optimal agitator power $P$ and vessel capacity $V$ :

The process of determining optimal values of a function requires us to use partial derivatives (Stewart). First, we must develop a total cost function that accurately portrays the costs of all involved elements of the extraction process on an annual basis. Thus, the total annual cost $C_{T}$ is given by

$$
C_{T}=C_{E}+C_{B}+C_{V}+C_{A}
$$

where $C_{E}$ and $C_{B}$ are the total annual costs of electricity and solvent $B$, respectively.

Now we must develop terms for the annual cost of electricity and solvent $B$. The cost of electricity per $k W \cdot h r$ is fixed, so the cost of electricity varies with the amount of batches run per year, $n$ :

$$
C_{E}=T \cdot P \cdot n \frac{\$ 0.1}{k W \cdot h r}
$$

Similarly, the cost of solvent $B$ varies with the amount of batches per year such that: 


$$
C_{B}=N_{B} \cdot n \cdot \frac{\$ 0.05}{k g}
$$

Combining equations (5)-(9) leads us to the annual cost equation:

$$
C_{T}=T P n \frac{\$ 0.1}{k W \cdot h r}+N_{B} n \frac{\$ 0.05}{k g}+20 V^{0.6}+90 P^{0.7} .
$$

The equation above is the total annual cost equation for the extraction process. But, since it incorporates other variables in addition to $P$ and $V$ (which we are optimizing through partial derivatives), substitutions must be made. This involves writing the equation in terms of $n$ and $P$. This conclusion can be drawn due to the constraints placed upon these particular values. The amount of batches per year, $\mathrm{n}$ is constrained by the total value of product $\mathrm{A}$ that is manufactured per year. AGIEX makes $10,000 \mathrm{~kg}$ of $A$ on a yearly basis, which dictates the optimized amount that can be run in each batch. Determinately, $n$ and $P$ are directly related to one another. As $n$ increases, agitator usage - and power $p$, increases as well.

$N_{A}$ can be rewritten as $10,000 / n$, and plugging it into (1) yields an $N_{B}$ value of $18,000 / n$. Combining these two terms into the vessel volume equation gives us: $V=30,000 / n$ which then produces $T=10(30,000 / n)^{0.5} / p^{1.2}$ after inserting $V$ into (4). Then, incorporating these numbers into the cost equation we see that:

$$
C_{T}(n, P)=\frac{\sqrt{30,000} \sqrt{n}}{P^{0.2}}+900+\frac{20\left(30,000^{0.6}\right)}{n^{0.6}}+90 P^{0.7},
$$

and we minimize this cost by computing the values of $n$ and $P$ for which $\frac{\partial C_{T}}{\partial n}=\frac{\partial C_{T}}{\partial P}=0$. 


\section{DISCUSSION}

After minimizing the total annual cost function in (11), the optimal operational parameters for the agitator are as follows:

\begin{tabular}{|c|c|c|}
\hline 1) & $\begin{array}{l}\text { Optimal agitator power } P \text { : } \\
\text { Optimal vessel capacity: }\end{array}$ & $\begin{array}{l}5.08 \mathrm{~kW} \\
486.46 \mathrm{~L}\end{array}$ \\
\hline 2) & $\begin{array}{l}\text { Corresponding batch time } T \text { : } \\
\text { Number of batches per year } n \text { : }\end{array}$ & $\begin{array}{l}31.37 \text { hrs } \\
61.67 \text { batches }\end{array}$ \\
\hline 3) & Optimal annual operation time: & $1,934.59 h r s / y r$ \\
\hline 4) & $\begin{array}{r}\text { Annual cost of electricity: } \\
\text { Annual cost of agitator: } \\
\text { Annual cost of vessel: } \\
\frac{\text { Annual cost of solvent } B}{\text { Total annual cost: }}\end{array}$ & $\begin{array}{r}\$ 982.77 \\
+\$ 280.77 \\
+\$ 818.95 \\
+\$ 900.01 \\
\$ 2,982.50\end{array}$ \\
\hline
\end{tabular}

Table 1: Optimal operational parameters of the agitator to minimize the cost of producing product A.

The annual cost of the vessel is higher than that of the agitator. The agitator is an element of the vessel and allows the reactions in the vessel to take place. It ensures that the chosen concentration of $A$ is reached.

These conclusions infer the approximate annual cost that companies will face in the chemical extraction of impurities in their products. The impurity was reduced by $10 \%$ in this instance. Also, the annual cost and relations are based on the company's output of $10,000 \mathrm{~kg}$ of liquid product $A$. Hence, it is reasonable to forecast that a higher vessel volume will be needed if more output is necessary to further supply manufacturing firms or other customers this company may have. This higher vessel volume will lead to higher costs along the array of operation costs in this extraction process. A higher output leads to higher costs and more running time for the vessel and agitator. This effect can be anticipated inversely in lower output. 
Notwithstanding, ideal, optimized conditions and measurements will be altered if any other output level is sanctioned contrary to the original amount that was used for calculations.

\section{CONCLUSIONS AND RECOMMENDATIONS}

In summary, the process of chemical extraction in question will cost AGIEX \$2,982.50 per year. The cost goes toward purification of product $A$ using a solvent $B$ and an extraction vessel with an agitator, as shown in Figure 1.

We recommend that the project be carried forward if financially feasible. One element that this company must note is that the amount of $N_{B}$ used in each batch, $n$, is higher than that of $N_{A}$. Although solvent $B$ is needed to produce a lower impurity level product $A$, using more solvent than the product itself needs to be analyzed by the company. Other solvent options may be available, but the integrity of the product and the cost of other solvents must be the main consideration in potentially selecting a solvent that requires less mass per batch. 


\section{NOMENCLATURE}

\begin{tabular}{|c|c|c|}
\hline Symbol & Description & Unit \\
\hline$P$ & Optimal agitator power & $k W$ \\
\hline$V$ & Optimal vessel volume & $L$ \\
\hline$N_{A}$ & Liquid product & $k g$ \\
\hline$X_{0}$ & $\begin{array}{l}\text { Impurity of product } A \\
\text { (initial, before batch extraction) }\end{array}$ & $\frac{k g \text { of impurity }}{k g \text { of } A}$ \\
\hline$N_{B}$ & Immiscible solvent & $\mathrm{kg}$ \\
\hline$Y$ & Impurity of solvent & $\frac{\mathrm{kg} \text { of impurity }}{\mathrm{kg} \text { of } B}$ \\
\hline$n$ & Batches per year & - \\
\hline$K$ & $\begin{array}{l}\text { Partition coefficient } \\
\text { (constant, equal to } 5 \text { for this system) }\end{array}$ & - \\
\hline$v_{A}$ & Specific volume of $A$ & $L / k g$ \\
\hline$v_{B}$ & Specific volume of $B$ & $L / k g$ \\
\hline$T$ & Batch time & hours \\
\hline$C_{T}$ & Total annual cost & $\$ / y r$ \\
\hline$C_{E}$ & Annual cost of the electricity & $\$ / y r$ \\
\hline$C_{V}$ & Annual cost of the vessel & $\$ / y r$ \\
\hline$C_{A}$ & Annual cost of the agitator & $\$ / y r$ \\
\hline$C_{B}$ & Annual cost of solvent $B$ & $\$ / y r$ \\
\hline
\end{tabular}

\section{REFERENCES}

Esrafili, A. e. (2012). Automated Preconcentration And Analysis Of Organic Compounds By On-Line Hollow Fiber Liquid-Phase Microextraction-High Performance Liquid Chromatography. (ScienceDirect., Ed.) Journal Of Chromatography A 1262, 27-33.

Li, S. e. (2007). Recovery Of Fumaric Acid From Industrial Wastewater By Chemical Extraction And Stripping. (S. C. Index, Ed.) Separation Science And Technology, 42(10), $2347-$ 2360 .

Stewart, J. (2012). Essential Calculus: Early Transcendentals. Mason, Ohio: Cengage Learning. 